\title{
Pedagogical Innovation Through Use of Elec- tronic Portfolios in Higher Education
}

\section{Innovación Pedagógica a Través del Uso de Portafolios Electrónicos en la Educación Supe- rior}

Ximena Elizabeth Naranjo Lozada ${ }^{1}$, Silvia Elizabeth Cárdenas Sánchez ${ }^{2}$, and Jessica Valentina Galimberti ${ }^{3}$

${ }^{1}$ Universidad Técnica de Ambato, Centro de Idiomas, Ambato, Ecuador

${ }^{2}$ Escuela Superior Politécnica de Chimborazo, Sede Morona Santiago, Macas, Ecuador

${ }^{3}$ Escuela Superior Politécnica de Chimborazo, Sede Morona Santiago, Macas, Ecuador

\section{Abstract}

The use of electronic folders implies processes and dedication of both the student and the teacher to be able to develop the final product that demonstrates the development and growth of the student in the subject and promotes both formative and summative evaluation. Through the following study, it is proposed to know if students consider the use of appropriate electronic portfolios in English in higher education. In addition, it is important to understand the implications of the development of electronic portfolios based on the experiences obtained during the semester in which the strategy was implied. This qualitative study was carried out at the Escuela Superior Politécnica de Chimborazo Morona Santiago headquarters during the special academic period April - August 2020. It is important to mention that the use of the Pathbrite application was chosen to prepare the portfolio since you can add videos, text, images and other addresses or web pages to make up the portfolio. Thanks to the survey, it was also possible to know how it influenced personal growth and the improvement of the students' English level.

Keywords: E-portfolio, innovation, foreign language, higher education

\section{Resumen}

El uso de portafolios electrónicos implica procesos y dedicación tanto del estudiante como del docente para poder elaborar el producto final que demuestre el desarrollo y crecimiento del alumno en la asignatura y se promueva una evaluación tanto formativa como sumativa. A través del siguiente estudio se plantea conocer si los estudiantes consideran el uso de los portafolios electrónicos adecuados en la enseñanza del inglés en la educación superior. Además, se pretende entender las implicaciones que tiene la elaboración de portafolios electrónicos en base a las experiencias obtenidas durante el semestre en el cual se ejecutó la estrategia. El presente estudio cualitativo se realizó en la Escuela Superior Politécnica de Chimborazo Sede Morona Santiago durante el periodo académico especial abril - agosto 2020. Es importante mencionar que se optó por el uso de la aplicación Pathbrite para elaborar el portafolio ya que con esta herramienta se puede añadir videos, texto, imágenes y otras direcciones o páginas web para elaborar el portafolio. A través de la encuesta también se pudo conocer cómo influyó en el crecimiento personal y en el mejoramiento del nivel de inglés de los estudiantes. 


\section{Introducción}

Con el uso de las herramientas tecnológicas que están al alcance de la mayoría de la sociedad en la actualidad, en el campo de la educación se ha insertado e implementado diferentes herramientas que ayudan a alcanzar los logros y objetivos ya sean macro o micro curriculares. En términos de innovación educativa el docente a través de la investigación y el uso de herramientas educativas implementa materiales o prácticas de enseñanza que apoyan en el proceso dentro y fuera del aula demostrando así que al momento de innovar, los cambios son evidentes y más aún cuando existe la tecnología al alcance de todos. Desde esta perspectiva, los portafolios electrónicos o también conocidos según García [1] como carpetas digitales, ePortafolio, e-Portafolio, web-Folio o e-Folio, se han vuelto una tendencia en la actualidad. Sánchez [2] manifiesta que el portafolio electrónico en términos generales permite la posibilidad de comunicar ideas, pero en el ámbito educativo lo conceptualiza como la recolección de trabajos que conlleva un proceso o pasos de reflexión, autoevaluación, aprendizaje y es una metodología de enseñanza donde la autenticidad es elemental al momento de evaluar. Según López [3] los portafolios electrónicos pueden ser un reflejo del esfuerzo, progreso y objetivos que el estudiante ha alcanzado ya sea en una o más asignaturas. Con lo expuesto, el siguiente estudio se centra en la asignatura de inglés donde el uso de portafolios se propone como alternativa a las estrategias tradicionales; así como también aprovechando de manera oportuna la posibilidad de usar la tecnología en la época que estamos viviendo.

Distintas investigaciones se han llevado a cabo en este campo en las cuales se propone y sugiere el uso de portafolios electrónicos en base a revisiones de literatura $y$ en otros casos exponen los beneficios del mismo, luego de experimentar y brindar resultados favorecedores en cuanto al uso de portafolios en el área educativa. La aplicación o uso del portafolio puede empezar desde la escuela y llegar hasta el sistema universitario. El presente trabajo se enfoca en el ámbito universitario. Cabero [4] menciona que usar un portafolio universitario ayuda a mejorar la evaluación formativa y facilita el proceso de autoevaluación. Además manifiesta que como resultado de la investigación cualitativa llevada a cabo con 102 estudiantes universitarios cuyo propósito principal era elaborar portafolios electrónicos en forma grupal para conocer el nivel de motivación y reflexión alcanzado durante la implementación del mismo, se pudo concluir que ayudan a la práctica educativa ya que son didácticos y el estudiante puede desarrollar su criticidad y ser reflexivo a la vez. Guasch [5] sugiere que es esencial que se conozca desde el inicio el objetivo para elaborar el portafolio mismo que debe ser claro y preciso lo cual también incluye saber muy bien qué tipo de diseño tanto pedagógico como tecnológico. Prendes [6] menciona que no es necesario incluir todo trabajo en un portafolio sino saber elegir que tarea o material es relevante y va a ser útil para el aprendizaje.

Por otra parte, se han realizado investigaciones en el uso de portafolios para evaluar las destrezas del idioma inglés como es la escritura. Lunar [7] en su estudio concluyó que el portafolio electrónico fue útil para implementar una evaluación a la destreza de escribir en el idioma inglés puesto que los estudiantes demostraron una actitud 
positiva, motivación y entusiasmo al momento de ir mejorando sus trabajos escritos. Además, casi en su totalidad, los participantes del estudio mostraron su satisfacción al conocer su progreso en la producción de los escritos en el idioma inglés. Thang [8] por su parte concluyó con su estudio que el uso de portafolios electrónicos en el aprendizaje de un idioma ayuda al desarrollo psicológico, pedagógico y tecnológico. Perdomo [9] en su estudio desarrollado cuasi experimental menciona que el uso de portafolios electrónicos es una alternativa para promover la evaluación cuando se promueve una educación constructivista y que se debería implementar desde contextos previos a la educación superior. Baturay [10] también concluye en su estudio que el e-portafolio es muy usado para trabajar en aprendizajes basados en problemas y ayuda a desarrollar la creatividad mientras aprenden el idioma. Barberà [11] sugiere que el portafolio ayuda en la formación del estudiante universitario pero a su vez ayuda en el futuro en la parte profesional. Yubero [12] concluye que si se usa la tecnología en éste proceso se lograría mejores resultados ya que los cambios son esenciales y más aún en la parte educativa. Pérez [13] también manifiesta que es necesario considerar el uso de portafolio electrónico en el aula como una herramienta que evalúe formativamente al estudiante y se estimule su aprendizaje significativo. Zambrano [14] finalmente menciona que el portafolio electrónico fomenta la creatividad y la autonomía del estudiante de cualquier nivel. Con lo expuesto, el uso de las carpetas electrónicas implica procesos y dedicación tanto del estudiante como del docente para poder elaborar el producto final que demuestren el desarrollo y crecimiento del alumno en la asignatura y se promueva una evaluación tanto formativa como sumativa. Wade [15] sostiene que también el desarrollo profesional del docente es fundamental dentro de la implementación de herramientas tecnológicas.

A través del siguiente estudio se plantea conocer si los estudiantes consideran el uso de los portafolios electrónicos adecuados en la enseñanza del inglés en la educación superior. Además, se pretende entender las implicaciones que tiene la elaboración de portafolios electrónicos en base a las experiencias obtenidas durante el semestre en el cual se ejecutó la estrategia.

\section{Materiales y Métodos}

El presente estudio cualitativo se realizó en la Escuela Superior Politécnica de Chimborazo Sede Morona Santiago durante el periodo académico especial abril - agosto 2020. Los participantes fueron 72 estudiantes dentro de los cuales eran 34 mujeres y 38 hombres que tomaron las clases de inglés 1 e inglés 2 . Los estudiantes de inglés 1 pertenecieron a la carrera de Ingeniería Ambiental, por otra parte, los estudiantes de inglés 2 pertenecían a la carrera de Contabilidad y Auditoría y de Zootecnia. En cuanto a la experiencia previa en el uso de portafolios electrónicos, 66 estudiantes manifestaron que era la primera vez que elaboraban un portafolio electrónico en su vida estudiantil. Mientras que 5 estudiantes ya habían utilizado las carpetas electrónicas antes de iniciar el semestre y solo 1 estudiante ha tenido la experiencia de elaborar un portafolio electrónico antes de iniciar los estudios universitarios. 
Se implementó el uso de portafolios desde la primera semana de clases donde se instruyó a los estudiantes para que puedan manejar y entender el propósito de los portafolios electrónicos siguiendo los pasos de construcción, recolección de evidencias y presentación del portafolio en cada parcial. Es importante mencionar que se optó por el uso de la aplicación Pathbrite para elaborar el portafolio ya que con esta herramienta se puede añadir videos, texto, imágenes y otras direcciones o páginas web para elaborar el portafolio. A través de la elaboración de las primeras actividades que debían evidenciarse en el portafolio electrónico fueron apareciendo los problemas en cuanto al manejo de la herramienta. Sin embargo, con la explicación efectiva y oportuna del docente investigador los participantes empezaron a entender y manejar todos los recursos disponibles en la página web.

Los estudiantes elaboraron videos, trabajos escritos, desarrollaron tareas de vocabulario y adjuntaron actividades grupales e individuales realizadas en otras herramientas y que se puede adjuntar a página de Pathbrite.

Luego de trabajar todo el semestre y con una revisión del portafolio electrónico en cada parcial se concluyó con el producto final al finalizar el semestre donde los estudiantes mediante una rúbrica realizaron la coevaluación y se asignó un puntaje. De igual manera, al final se entrevistó a un total de 30 estudiantes del total de participantes quienes respondieron a una serie de preguntas relacionadas con las ventajas y desventajas que encontraron durante el proceso de construcción del portafolio electrónico. También, los estudiantes participantes respondieron a una encuesta elaborada para conocer el impacto que tuvo el portafolio electrónico en su aprendizaje del idioma inglés. El cuestionario tuvo como objetivo conocer cómo influyó en el aprendizaje del idioma inglés la recolección de información, trabajos y artefactos que se incluyó en el portafolio. De igual manera el cuestionario recolectó datos de las experiencias previas en cuanto al uso de portafolios como la obtención de sugerencias para implementar el portafolio electrónico no solo en la asignatura de inglés; sino en otras asignaturas.

\section{Resultados}

A partir de la aplicación de una encuesta y de entrevistas individuales, se pudo recabar información relevante que se va a detallar a continuación.

Los resultados de la encuesta refleja un punto principal e importante a considerar para la implementación de portafolios electrónicos no solo en la asignatura de inglés sino en otras asignaturas. Del total de participantes que completaron la encuesta, el $88 \%$ manifestó que si sugeriría a otros docentes el uso del portafolio electrónico como alternativa de evaluación del aprendizaje. Mientras que el 12\% manifestó que no se podría usar en otras asignaturas.

Retomando el uso del portafolio electrónico en la asignatura de inglés, los estudiantes manifestaron si es o no necesario incluir los siguientes elementos en un portafolio en base a su experiencia. Como se puede apreciar en el gráfico, todos los elementos son considerados de manera positiva para incluir en un portafolio electrónico. Al mencionar lecturas y redacciones en inglés, 61 estudiantes que representan el 85\% de los encuestados, sí sugieren incluir tareas o actividades de lectura en una carpeta 
digital. Mientras que 64 participantes que es el $89 \%$ sí sugiere que se adjunten videos en un portafolio. el $75 \%$ sugiere poner audios y el $79 \%$ de encuestados menciona que si es necesario incrementar ejercicios gramaticales en el portafolio electrónico. Ver gráfico 1.

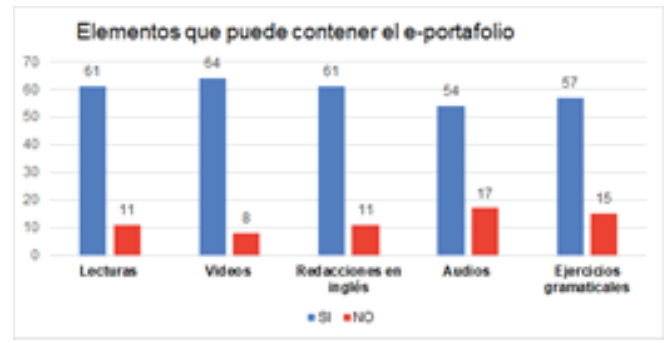

Figure 1

Sugerencia de elementos que debe contener un portafolio electrónico en la asignatura de inglés.

A través de la encuesta también se pudo conocer la forma que influyó en el crecimiento personal y en el mejoramiento del nivel de inglés de los estudiantes. Para lo cual se preguntaron sobre varios aspectos que radican en el contexto del manejo del portafolio y la autoevaluación. Ver Tabla 1.

\section{Table 1}

Opinion personal sobre la metodología y ventajas de usar portafolios en las clases de inglés.

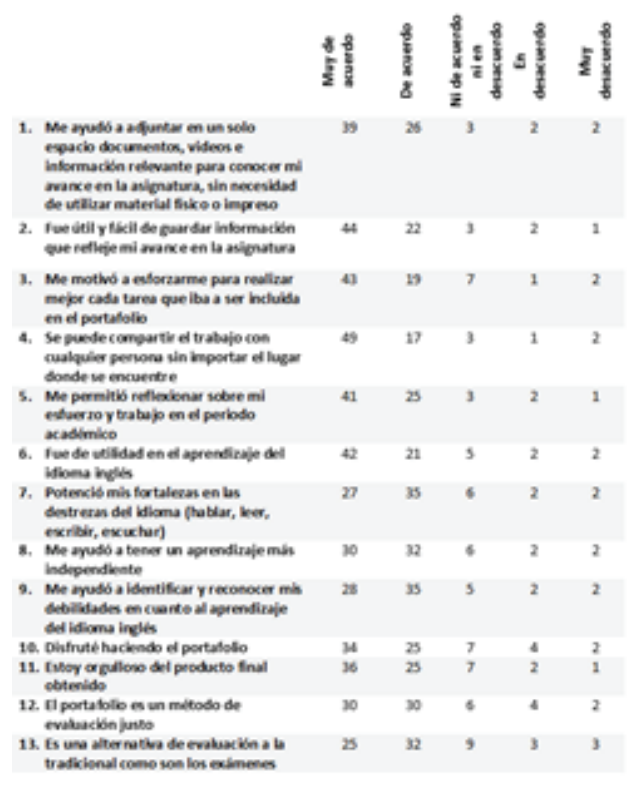

Según los datos que se puede observar en la tabla, el 54\% menciona que está muy de acuerdo en que el portafolio les ayudó a adjuntar en un solo espacio documentos, videos e información relevante; mientras que un 36\% menciona en el mismo item que esta de acuerdo. Por otra parte, el $61 \%$ está muy de acuerdo y el $31 \%$ está de acuerdo en que fue útli y fácil de guardar información lo cual reflejaba el avance en la asignatura 
de inglés. El $60 \%$ considera que esta muy de acuerdo en que el uso de portafolios electrónicos les motivó a esforzarse más en cada tarea y el $26 \%$ está de acuerdo en el mismo item. Con el $57 \%$ de muy de acuerdo y el $35 \%$ de acuerdo en el item donde se menciona que el portafolio electrónico les permitió reflexionar sobre el esfuerzo individual y el trabajo se entiende que hay una aceptación en uno de los principales objetivos del uso de portafolios electrónicos en clases. También están my de acuerdo (68\%) y de acuerdo (24\%) que el trabajo se puede compartir con la persona que se desee sin importar el lugar donde se encuentre. Un punto referencial e importante es saber que el $58 \%$ de participantes están muy de acuerdo y el $29 \%$ de acuerdo en que el portafolio electrónico fue de utilidad en el aprendizaje del idioma inglés así como también potenció las destrezas del idioma como son leer, hablar, escribir y escuchar con un $38 \%$ muy de acuerdo y un $49 \%$ de acuerdo. Al considerar que el portafolio es un instrumento de evaluación justa y permite al estudiante ser más independiente, el $42 \%$ mencionó estar muy de acuerdo mientras que el $44 \%$ dijo estar de acuerdo. Un punto importante que mencionar es que el $50 \%$ de estudiantes dice estar muy de acerudo en que elproducto final cumplió con sus expectativas y están orgullosos del trabajo y el 35\% dice estar de acuerdo. Finalmente, el 35\% dice que está muy de aceurdo que el uso de portafolios electrónicos es una alternativa de evalaucón diferente a lo tradicional y el $44 \%$ menciona estar de acuerdo.

Es importante también contabilizar los datos que representan los diferentes puntos de vista en cuanto a la utilización del portafolio electrónico en el aprendizaje del idioma inglés. Los resultados de la encuesta demuestran que en base al material obtenido de las entrevistas individuales, se puede destacar que la mayoría de entrevistados advierte que el uso de portafolios fue una forma creativa de trabajar en clases y que ayudaba a realizar las tareas:

nos ayuda a mantenernos más ordenados en cuanto a llevar la materia y podemos adjuntar material de estudio (entrevistado 1).

$\mathrm{mmm}$ es muy interactivo $y$ en vez de estar usando el cuaderno, es una buena forma de practicar inglés (entrevistado 2).

al principio como no sabía utilizar mucho fue mi problema y tuve que investigar pero después creo que fue una gran herramienta porque podía revisar la materia y me ayudó mucho (entrevistado 3).

al comienzo fue complicado porque no conocía el diseño y no sabía como crear o agregar imágenes, pero después fue fácil para enviar tareas (entrevistado 4).

En cuanto al uso de la herramienta Pathbrite que está disponible en la web, 69 estudiantes de un total de 72 manifestaron que es útil y se seguirán utilizando en el caso de ser necesario. De igual manera en las entrevistas mencionaron que:

a mi parecer pathbrite es una buena aplicación eh y que tiene varias herramientas útiles, bueno a mi parecer estuvo bien y me ayudó a guardar trabajos que pude revisar después para estudiar (entrevistado 5). 
Cabe destacar que durante el proceso de aplicación de la estrategia los estudiantes no mencionaron tener problemas en cuanto a subir documentos, fotos, o videos ya que la seguridad que provee la página solamente permite manipular al usuario que con su contraseña puede determinar con quien compartir el link.

\section{Discusión}

Tras un sondeo inicial, se percibe que los estudiantes están acostumbrados a comunicarse en entornos digitales, pero no de forma metacognitiva y metalingüística. Se considera necesaria la implementación de actividades diferentes en el aprendizaje del idioma extranjero. También el tipo de habilidades y estrategias lingüísticas que se enseñan en el aula de lenguas ha sido necesario renovar para que los estudiantes puedan comunicarse de un modo efectivo en los entornos digitales, como lo es por ejemplo, el portafolio digital.

El uso de portafolios o carpetas digitales demuestra un recurso importante en el aprendizaje de los estudiantes. Como se pudo verificar, los portafolios ayudan a que el estudiante organice la información y pueda desarrollar actividades de una manera más creativa y didáctica. Según las encuestas y entrevistas realizadas a los participantes, no solo se puede usar el portafolio electrónico en la asignatura de inglés sino en otras asignaturas ya que permiten aprender de mejor manera y se puede repasar la materia usando la información recaba en los portafolios. Así, el estudiante puede reflexionar y darse cuenta de las ventajas que ofrece el uso apropiado de estos recursos. Por lo tanto, el rol del profesor es fundamental y consiste en facilitarle al estudiante las herramientas necesarias para la adquisición de los contenidos digitales de la asignatura.

Esta herramienta ha fomentado la coevaluación y en especial la autoevaluación y reflexión sobre cuáles son sus conocimientos y sus carencias con respecto a la lengua. El uso del e-portafolio ha sido un modo diferente de aprendizaje-enseñanza.

\section{Conclusiones}

La herramienta digital del portafolio electronico es un medio que une las nuevas metodologias del docente, metodos de evaluacion, tecnologías y procesos donde se enfatiza en una innovación pedagógica que se enfoca en el pensamiento critico del estudiante, que resulta ser el protagonista del proceso enseñanza-aprendizaje, no solo de un idioma extranjero, sino tambièn de cualquier otro tipo de asignatura. Al concluir la presente investigación, se pudo entender que el uso de herramientas digitales para recolectar información que documente el aprendizaje de cada estudiante conllevó a percibir favorablemente la importancia y relevancia de los portafolios electrónicos en la asignatura de inglés. Cabe mencionar que el porcetanje de estudiantes que tuvieron su primera experiencia en el uso de protafolios electrónicos fue alto durante este estudio lo cual significa que se peude seguir promocionando y propiciando espacios para que tanto docnetes como estudiantes usen las carpetas electrónicas como un recurso de evalaución diferente a la tradicional donde el estudiante es responsable de su trabajo 
y mediante su esfuerzo permanente al final relfreje un producto que alcanzó a través del proceso enseñanza- aprendizaje.

\section{Agradecimientos}

A la ESPOCH Sede Morona Santiago por tan importante iniciativa de ceder espacios para divulgar ciencia e investigación que engrandece a la población en general.

\section{Conflicto de Intereses}

No existieron intereses particulares o de alguna entidad en el presente estudio.

\section{References}

[1] García DF. El papel de los portafolios electrónicos en la enseñanza-aprendizaje de las lenguas. Geohistoria5 [Internet]. 2005 August 1. Available from: http://files.geohistoria5.webnode.es/ 200000009-dcd1eddcbf/10.pdf

[2] Sánchez VM. El portafolio electrónico. 2007. Available from: https://digitum.um.es/digitum/bitstream/ 10201/13418/1/portafolio.pdf

[3] López ME, Jaén MA, Cabero AJ. Los portafolios educativos virtuales en las aulas universitarias. Instrumentos didácticos para la innovación docente y la calidad de los procesos de enseñanza y aprendizaje. Idus.us.es. 2013;31(1):43-70.

[4] Cabero AJ, López ME, Llorente CM. E-Portafolio universitario como instrumento didáctico 2.0 para la reflexión, evaluación e investigación de la práctica educativa en el espacio europeo de educación superior. VEsC. 2012;3(4):27-46.

[5] Guasch T, Guàrdia OL, Barberá E. Prácticas del portafolio electrónico en el ámbito universitario del estado español. Red [Internet]. 2009 April 30. Available from https://revistas.um.es/red/article/view/ 69611

[6] Prendes E, Ma P, Sánchez V, del Mar M. Portafolio electrónico: posibilidades los docentes. Pixel-Bit. Revista de Medios y Educación. 2008; (32):21-34.

[7] Lunar L. El portafolio: estrategia para evaluar la producción escrita en inglés por parte de estudiantes universitarios. Ve.scielo.org. 2007;24:63-96.

[8] Thang S, Lee $\mathrm{Y}$, Zulkifli $\mathrm{N}$. The role of the electronic portfolio in enhancing information and communication technology and English language skills: the voices of six Malaysian undergraduates. Taylor \& Francis. 2020

[9] Perdomo B. El portafolio como alternativa de evaluación en inglés para propósitos específicos. Revistas.14(3):32-51.

[10] Baturay M, Daloglu A. E-portfolio assessment in an online English language course. Taylor \& Francis. 2020. https://www.tandfonline.com/doi/full/10.1080/09588221.2010.520671?src=recsys

[11] Barberà E, Gewerc BA, Rodríguez IJL. Portafolios electrónicos y educación superior en España: Situación y tendencias. Red. 2016;(50).

[12] Yubero J. Herramientas multimedia en la enseñanza de lenguas extranjeras: un recurso motivador Dugi-doc.udg.edu. [Internet]. 2020. Available from https://dugi-doc.udg.edu/handle/10256/2793

[13] Pérez M. Uso de portafolio para educación personalizada. Dialnet. [Internet]. 2020. Available from: https://dialnet.unirioja.es/servlet/articulo?codigo $=5385920$

[14] Zambrano PM. El e-PEL, una herramienta para desarrollar las competencias básicas en lenguas extranjeras. Repositorio.unican.es. [Internet]. 2020. Available from: https://repositorio.unican.es/xmlui/ handle/10902/5063

[15] Wade A, Abrami P, Sclater J, Sclater J. An Electronic portfolio to support learning. Learntechlib.org [Internet]. 2020. Available from: https://www.learntechlib.org/p/43167/ 